\title{
NECK SUPPORT PADA HEAD CONTROL EXERCISE LEBIH MENINGKATKAN KEMAMPUAN FUNGSIONAL BERJALAN ANAK CEREBRAL PASLY SPASTIK DIPLEGI DI YAYASAN PENDIDIKAN ANAK CACAT (YPAC) JAKARTA
}

\author{
Agus Frandes Sariaman ${ }^{1}$, I Ketut Suyasa², Muhammad Irfan $^{3}$, Luh Putu Ratna Sundari ${ }^{4}$, \\ I Made Krisna Dinata ${ }^{4}$, I Putu Adiartha Griadhi ${ }^{4}$. \\ ${ }^{1}$ Program Studi Magister Fisiologi Keolahragaan Universitas Udayana, Denpasar \\ ${ }^{2}$ Fakultas Kedokteran, Universitas Udayana, Denpasar \\ ${ }^{3}$ Fakultas Fisioterapi Universitas Aisyah, Yogyakarta \\ ${ }^{4}$ Departemen Ilmu Faal Fakultas Kedokteran, Universitas Udayana, Denpasar \\ E-mail: agusfrandes09@yahoo.co.id
}

\begin{abstract}
ABSTRAK
Pendahuluan: Aktivitas motorik anak cerebral palsybiasanya mengalami keterlambatan activity daily livingyang dipengaruhi olehhead control, karena kepala berfungsi dalam melawan gravitasi dan sebagai inisiasi gerakan awal saat berjalan. Penelitian ini dilakukan dengan hipotesis bahwa penambahan neck support pada head control exercise lebih baik dalam peningkatan kemampuan fungsional berjalan anak $\mathrm{CP}$ spastic diplegic.

Materi \& Metode: Penelitian merupakan studi eksperimental dengan rancangan pre test and post test control group design. Jumlah responden sebanyak 14 sampel yang dibagi menjadi 2 grup secara random, pada kelompok kontrol mendapat head control exercise, pada kelompok perlakuan mendapatneck support dan head control exercise. Fungsional berjalan yang di teliti dengan diukur dengan GMFM, perlakuan diberikan selama 8 minggu.

Hasil Penelitian: Dari hasil penelitian terdapat peningkatan fungsional berjalan yang signifikan pada anak Kelompok kontrol yang mendapatkan intervensi head control exercise dengan nilai pre $(17,31 \pm 5,06)$ dan nilai post $(18,30 \pm 3,16)$ didapat nilai $\mathrm{p}=0,011$. Terdapat peningkatan fungsional berjalan yang signifikan pada kelompok perlakuan yang mendapat intervensi neck supportdan head control exercise dengan nilai pre $(15,53 \pm 4,23)$ dan nilai post $(24,59 \pm 4,98)$ dengan didapat nilai $\mathrm{p}=0,001$. Terdapat perbedaan yang signifikan pada peningkatan fungsional berjalan pada Kelompok kontrol yang mendapatkan head control exercise dan pada Kelompok perlakuan yang mendapat neck support dan head control exercise dengan nilai Kelompok kontrol ( 18,30 \pm 4,96 ) dan nilai pada Kelompok perlakuan $(24,59 \pm$ 4,98) dan didapat nilai $\mathrm{p}=0,036$.

Simpulan: Penelitian ini dapat disimpulkan bahwa penambahan neck support pada head control exercise lebih baik dibandingkan hanya head control exercise dalam meningkatkan fungsional berjalan anak CPspastic diplegic.
\end{abstract}

Kata kunci : Head control exercise, neck support, fungsional berjalan, cerebral palsy spastik diplegi. 


\title{
NECK SUPPORT OF HEAD CONTROL EXERCISE IN IMPROVE FUNCTIONAL WALKING ABILLTY OF CHILDREN WITH CEREBRAL PALSY SPASTIC DIPLEGIC AT YPAC JAKARTA
}

\begin{abstract}
Introduction: The motor activity of cerebral palsy children usually having activity daily living problem affected by head control because the head functions in fighting gravity and as initial initiation of movement when walking. This study was conducted with the hypothesis that addition of neck supports to head control exercise increasing functional walking ability better in spastic diplegi cerebral palsy children.
\end{abstract}

Material \& Method: This research was an experimental study with a pre-test and posttest control group design as the research design. The number of respondents were 14 children diagnosed with spastic cerebral palsy diplegi. Respondents were divided into 2 groups randomly, in the control group given head control exercise and in the treatment group given a neck support + head control exercise. Functional walking is a matter of interest in this study as measured by GMFM, this study was conducted for 8 weeks.

Results: There was a significant functional improvement in the control group children who received head control exercise intervention with pre values $(17.31 \pm 5.06)$ and post values $(18.30 \pm 3.16)$ a $\mathrm{p}$ value $=0.011$, there is a significant functional improvement in the treatment group that received neck support intervention and head control exercise with pre value $(15.53 \pm$ $4.23)$ and post value $(24.59 \pm 4.98)$ a value of $p=0.001$, There is a difference in functional walk in the control group that received head control exercise and in the treatment group that received neck support and head control exercise with the control group value $(18.30 \pm 4.96)$ and the value in the group treatment $(24.59 \pm 4.98)$ with a value of $p=0.036$.

Conclusion: From this study it can be concluded that the addition of neck supports to head control exercise is better than just head control exercise in improving functional walking of spastic diplegi cerebral palsy children.

Keywords: Head control exercise, neck support, functional walking, spastic diplegi cerebral palsy.

\section{PENDAHULUAN}

Anak merupakan anugerah terindah dalam semua keluarga. Semua orang tua pasti mengharapkan anak tersebut normal di tumbuh kembangnya, terkadang harapan hidup kita tidak sesuai dengan kenyatan. Di beberapa keluarga masih di temukan anak yang dititipkan Tuhan dengan kondisi anak special need childrenyang mempunyai kelainan atau penyimpangan dari kondisi dengan rata-rata normal umumnya sehingga gangguan tumbuh kembang terganggu ${ }^{1}$. Sehingga menjadi perhatian dan perawatan khusus keluarga dalam kehidupan anaknya nanti.Salah satu jenis ABK adalah cerebral palsy (CP). Cerebral Palsy merupakan gangguan permanen perkembangan gerakan dan postur tubuh serta menyebabkan keterbatasan aktivitas yang sering dikaitkan dengan gangguan pada otak ${ }^{2}$. Istilah ini biasanya dipakaiuntuk menerangkan adanya kelainan gerak, sikap ataupun bentuk tubuh, 
gangguan koordinasi yang disertai dengan gangguan psikologis dan sensoris yang disebabkan oleh adanya kerusakan atau kecacatan pada masa perkembangan otak. Anak CP spastik diplegi yang menjadi mengalamigangguan dalam motorik berjalan, sehingga anak mengalami gangguanactivity daily living(ADL) dalam kesehariannya. Anak CP spastik diplegi mengalami gangguan pada kortex cerebellum sehingga menyebabkan masalah dalam gangguan gerak. Hal ini terjadi karena head control anak CP spastik diplegi tidak stabil dan cenderung memiliki asimetris otot SCM, head control yang tidak stabil ini terjadi karena anak memiliki defisit persepsi visual dan strabismus yang menyebabkan anak mudah jatuh ${ }^{3}$. Keseimbangan saat berjalan anak CP kurang berkembang selama ADL. Sistem visual memegang peranan penting dalam menjaga keseimbangan karena sekitar dua puluh persen serabut saraf dari mata berinteraksi dengan sistem vestibular. Kondisi kepala ini memberikan pengaruh kepada fungsional berjalan, sehingga berakibat terganggunya keseimbangan anak CP spastik diplegi karena head control yang kurang baik. Gerakan berjalan merupakan tugas koordinasi yang sangat tinggi dikontrol oleh susunan saraf pusat dan melibatkan sistem lainnya ${ }^{4}$

Head Control exercise adalah bentuk latihan meningkatkan kontrol kepala yang diberikan untuk mengaktivasi otot SCM secara aktif dengan cara menstimulasi sistem visual dan audiotry. Head control berfungsi sebagai sistem vestibular yang bertujuan melawan gravitasi dan memberikan inisiasi awal saat gerakan.Head control exercise diberikan dengan 4 jenis latihan yaitu visual spasial perception, eye hand coordination, eye function center, dan chin tuck. Anak CP memiliki kepala cenderung flexi neck dan sedikit rotasi ke kiri maupun kanan.

Tujuan penelitian ini untuk membuktikan penambahan neck support pada head control exerciselebih baik dari pada head control exercise saja dalam meningkatkan fungsional berjalan anak cerebral palsy spastik diplegi.

\section{METODE PENELITIAN}

Penelitian ini studi eksperimental dengan rancangan pretest - posttest group design. Kelompok kontrol diberikan head control exercise, Kelompok perlakuan diberikan neck support dan head control exercise. Pengukuran pada fungsional berjalan menggunakan Gross Motor Function Meausure (GMFM). Masing masing perlakuan dilakukan 3 kali seminggu selama 8 minggu. Sampel merupakan pasien di YPAC Jakarta yang berjumlah 14 sampel yang berusia $4-15$ tahun yang dibagi 2 kelompok.

\section{HASIL PENELITIAN}

\section{Karakteristik Subjek Penelitian.}

Tabel 1

Karakteristik subjek penelitian (usia)

\begin{tabular}{lcccc}
\hline \multirow{2}{*}{$\begin{array}{c}\text { Karakteristik } \\
\text { Subjek }\end{array}$} & \multicolumn{2}{c}{ Kelompok kontrol } & $\begin{array}{c}\text { Kelompok } \\
\text { Perlakuan }\end{array}$ \\
\cline { 2 - 5 } & Jumlah & $\%$ & Jumlah & $\%$ \\
\hline $4-6$ Tahun & 1 & $14 \%$ & 0 & $0 \%$ \\
$7-9$ Tahun & 3 & $43 \%$ & 3 & $43 \%$ \\
$10-12$ Tahun & 0 & $0 \%$ & 1 & $14 \%$ \\
$13-15$ Tahun & 3 & $43 \%$ & 3 & $43 \%$ \\
\hline Jumlah & 7 & 100 & 7 & $100 \%$ \\
\hline
\end{tabular}

Berdasarkan tabel $1 \mathrm{di}$ atas penderita anak CP terbanyak ada pada usia 7-9 tahun dan 13-15 tahun.

Tabel 2.

Distribusi berdasarkan jenis kelamin

\begin{tabular}{clclc}
\hline \multirow{2}{*}{$\begin{array}{c}\text { Jenis } \\
\text { Kelamin }\end{array}$} & \multicolumn{2}{l}{ Kelompok kontrol } & \multicolumn{2}{l}{ Kelompok Perlakuan } \\
\cline { 2 - 5 } & Jumlah & $\%$ & Jumlah & $\%$ \\
\hline Laki - Laki & 4 & $57 \%$ & 6 & $83 \%$ \\
Perempuan & 3 & $43 \%$ & 1 & $17 \%$ \\
\hline Jumlah & 7 & $100 \%$ & 7 & $100 \%$ \\
\hline
\end{tabular}


Berdasarkan tabel 2 di atas penderita anak CP terbanyak menurut jenis kelamin pada kedua kelompok adalah laki-laki.

\section{Uji Normalitas dan Homogenitas}

Tabel 3

Uji Normalitas dan Homogenitas

\begin{tabular}{ccccc}
\hline & \multicolumn{2}{c}{ Normalitas } & \multicolumn{2}{c}{ Homogen } \\
\cline { 2 - 5 } Perlakuan & $\begin{array}{c}\text { Kelompok } \\
\text { kontrol }\end{array}$ & $\begin{array}{c}\text { Kelompok } \\
\text { perlakuan }\end{array}$ & $\begin{array}{c}\text { Kelompok } \\
\text { kontrol }\end{array}$ & $\begin{array}{c}\text { Kelompok } \\
\text { perlakuan }\end{array}$ \\
\cline { 2 - 5 } & p-value & p-value & p-value & p-value \\
\hline Sebelum & 0,376 & 0,102 & 0,647 & 0,883 \\
Sesudah & 0,275 & 0,245 & & \\
\hline
\end{tabular}

Hasil uji normalitas menggunakan shapiro wilk test didapatkan nilai $\mathrm{p}>0,05$ berartidata berdistribusi normal. Hasil uji homogenitas dengan menggunakan levene test didapatkan nilai $\mathrm{p}>0,05$ yang berarti data homogen.

\section{HeadControl Exercise terhadap peningkatan fungsional berjalan}

Tabel 4.

Hasil Uji Efek perlakuan terhadap kelompok kontrol

\begin{tabular}{cccc}
\hline Data & Mean & SD & P \\
\hline $\begin{array}{c}\text { Sebelum } \\
\text { perlakuan }\end{array}$ & 17,31 & 5,06 & \\
$\begin{array}{c}\text { Sesudah } \\
\text { Perlakuan }\end{array}$ & 18,30 & 3,16 & \\
\hline
\end{tabular}

Berdasarkan tabel 4 di atas, hasil uji dengan menggunakan paired sample $t$-test didapatkan nilai $\mathrm{p}=0,011$ dimana $\mathrm{p}<0,05$, hal ini dapat disimpulkan bahwa head control exercise meningkatkan fungsional berjalan anak CP spastik diplegi.

\section{Neck support dan Head Control Exercise Dalam Meningkatkan Fungsional Berjalan}

Tabel 5.

Hasil Uji Efek Perlakuan Terhadap

Kelompok Perlakuan

\begin{tabular}{cccc}
\hline Data & Mean & SD & P \\
\hline $\begin{array}{c}\text { Sebelum } \\
\text { Perlakuan }\end{array}$ & 15,53 & 4,23 & \\
$\begin{array}{c}\text { Sesudah } \\
\text { Perlakuan }\end{array}$ & 24,59 & 4,98 & 0,001 \\
\hline
\end{tabular}

Berdasarkan tabel 5 di atas, hasil uji dengan menggunakan paired sample t-test didapatkan nilai $\mathrm{p}=0,001$ dimana $\mathrm{p}<0,05$, hal ini dapat disimpulkan bahwa neck supportdan head control exercise meningkatkan fungsional berjalan anak $\mathrm{CP}$ spastik diplegi.

5. Neck support pada head control exercise lebih meningkatkan fungsional berjalan anak cerebral palsyspastik diplegi dibandingkan dengan head control exercise

Tabel 6.

Hasil Uji BedaSetelah Perlakuan Antara Kedua Kelompok.

\begin{tabular}{cccc}
\hline Kelompok & Mean & SD & P \\
\hline Kontrol & 18,30 & 4,96 & \\
& & & 0,036 \\
Perlakuan & 24,59 & 4,98 & \\
\hline
\end{tabular}

Berdasarkan tabel 6 diatas, hasil uji dengan menggunakan $t$ test independent didapatkan nilai $\mathrm{p}=0,036$ dimana $\mathrm{p}>0,05$, hal ini dapat disimpulkan bahwa neck supportlebih baik dari pada head control exercise dalam meningkatkan fungsional berjalan anak $\mathrm{CP}$ spastik diplegi.

\section{PEMBAHASAN}

Head control exercise meningkatkan fungsional berjalan anak cerebral palsy spastik diplegi

Head control exercise yang diberikan terdiri dari 4 teknik yaitu attention function center, visual spasial perception, eye hand coordination, dan chin tuck. Latihan kontrol kepala ini dapat meningkatkan sistem visual dan auditory karena posisi kepala dan sistem vestibular berada di kepala ${ }^{5}$.Pada head control exercise, kepala anak akan bergerak ke arah yang diinginkan terapis maka dari itu 
gerakan kepala yang dilakukan akan menyebakan reseptor sensorik propioceptif mengirim impuls ke otak, sehingga otak akan menstimulasi reseptor vestibular menjadi aktif. Informasi sensorik tentang gerak, keseimbangan, dan orientasi spasial yang telah disediakan oleh aparat vestibular (utrikulus, sakulus, dan tiga kanal yang berbentuk setengah lingkaran)disetiap telinga. Utrikulus dan sakulus berfungsi sebagai mendeteksi gravitasi (orientasi vertical) dan gerakan linear. Kanalis semikularis mendeteksi gerakan rotasi. Sistem vestibular ini mengirim kontor motor signal melalui otot ke saraf - saraf mata dengan otomatis sehingga terjadi proses vestibulo occularmotor refleks (VOR) yang aktif.

Gerakan kepala pun menyebabkan peningkatan impuls dari organ vestibular sehingga mengontrol gerakan mata dan menstabilkan pandangan. Adanya kontrol kepala menyebabkan adanya informasi pada visual yang mengaktifkan reseptor sensorik di retina sehingga dapat mengidentifikasi suatu bentuk objek.Oleh karena itu latihan harus dilakukan secara berulang ulang. Sebagai integrasi sensorik yang berlangsung, batang otak mengirimkan impuls ke otot yang mengontrol pergerakan mata, kepala, leher sehingga anak dapat mempertahankan keseimbangan kepala. Posisi kepala harus dikoreksi saat berjalan ${ }^{6}$ karena kepala yang stabil dapat melawan gravitasi dan inisiasi awal saat gerak dan akan berhubungan terhadap keseimbangan.

\section{Neck supportdan Head Control Exercise lebih meningkatkan fungsional berjalan anak Cerebral Palsy spastik diplegi}

Penambahan alat bantu dari luar neck support yang bertujuan support kepala dari luar. Neck support ini akan mengoreksi axis kepala dengan batang tubuh sebelum diberikan latihan head sehingga keseimbangan kepala lebih optimal saat diberikan latihan. Efek collar dapat membatasi gerak dari kepala secara maksimal ${ }^{7}$ namun pada penelitian ini dipakai jenis semi rigid sehingga tidak terlalu membatasi gerak kepala saat latihan.Collar membuatpanjang otot sternocleidomastoid (SCM) menjadi simetris untuk melawan gravitasi agar kepala tidak jatuh ke satu sisi saat melakukan aktivitas. Neck support memberikan sensori tactile pada otot SCM yang terelongasi dan memberikan kemampuan propioceptive yang optimal, sehingga meningkatkan sistem motorik pada kepala. Keseimbangan kepala sangat berhubungan dengan fungsional berjalan anak $\mathrm{CP}^{8}$ Posisi kepala yang disupport oleh neck support dapat menjadi lurus dengan posisi trunk dan pelvic sehingga base of support (BOS) dan center of gravity (COG) tetap berada diarea core atau abdominal saat berjalan, serta neck support diberikan ke sampel tanpa ada tarikan penuh agar aktivasi otot leher dapat tetap dilatih tanpa adanya stabilisasi pasif dari pada leher anak tersebut. Sehingga sistem sensoris pada anak dapat terstimulasi dengan baiknya dikarenakan fungsi visual dan vestibular yang lebih maksimal dengan neck support ini sehingga dapat mengoptimalkan dari pada VOR, VCR, dan VSR dalam menjaga keseimbangan kepala saat berjalan.

\section{Neck support Pada Head Control Exercise Lebih Meningkatkan Fungsional Berjalan Anak Cerebral PalsyDibandingkan Dengan Latihan Head Control}

Pada penambahanNeck support juga dapat membantu elongasi otot leher sehingga dapat teraktivasi secara maksimal sehingga saat diberikan latihan head control kekeuatan otot leher mampu secara maksimal. kekuatan otot meningkat menyebabkan kontrol yang lebih baik dari kepala melawan gravitasi ${ }^{9}$. mengatakan sejumlah keterampilan lainnya muncul, termasuk dagu tuck, perhatian visual yang maksimal ${ }^{10}$.

Menggunakan alat bantu neck supportpada anak cerebral palsy sangat membantu dalam mengoreksi axis tubuh karena terjadinya mobilisasi pada C1-C2 sehingga menyebabkan tonus postural menurun $^{11}$. Collar memberikan informasi kepada tactil didaerah otot SCM dan 
mengaktifkan propioceptive yang akan memberikan rangsangan kepada gerak kepala tanpa adanya perubahan posisi kepala yang jatuh. Chin tuck pun dapat memberikan informasi kepada trunk agar dapat mempertahankan postur menjadi lebih baik. Neck support merupakan alat bantu dari eksternal support pada kepala. Motivasi yang dimiliki anak juga sangat mempengaruhi untuk dapat melakukan intervensi yang benar terutama latihan yang bersifat aktif maka latihan dilakukan pada pagi hari tanpa menganggu aktivitas sekolahnya, jika anak mengalami moody peneliti memberikan reward berupa hadiah permen manis untuk anak dapat melakukan latihan kembali.

Visual juga sangat berpengaruh ketika anak tidak memiliki konsentrasi dan pandangan yang tidak fokus pada instruksi terapis akan sangat mengganggu maka dari itu latihan ini dilakukan pada ruangan khusus tanpa terganggu dengan kondisi ruangan yang ramai. Berdasarkan penjelasan diatas dapat di ambil kesimpulan bahwa penambahan neck supportpada head control exercise lebih baik terhadap fungsional berjalan anak cerebral palsy spastik diplegi.

\section{KETERBATASAN PENELITIAN}

Peneliti tidak dapat mengontrol aktivitas sampel di luar program latihan yang diberikan yang dapat mempengaruhi keseimbangan.

\section{SIMPULAN DAN SARAN}

Neck supportdengan latihan head control lebih baik dalam meningkatkan kemampuan fungsional berjalan anak cerebral palsy spastik diplegi dibandigkan dengan latihan head control.

Adapun saran yang dapat diberikan adalah :

1. Disarankan penggunaan neck support menjadi program latihan dirumah untuk pasien dan untuk program latihan fisioterapi karena dapat meningkatkan keseimbangan kepala saat beraktivitas.

2. Diharapkan pada penelitian berikutnya peneliti melakukan kontrol yang lebih baik lagi aktivitas sampel diluar program latihan yang diberikan.

\section{DAFTAR PUSTAKA}

1. Heward W.L. 2003. Exceptional Children An Introduction to Special Education. New Jersey: Merril, Prentice Hal

2. Campbell, Suzann K, Palisano, Robert J dan Orlin, Margo N. 2012. Physical Therapy for Children Fourth Edition. Missouri: Elseviers Saunders

3. Berker, Nadire. 2005. The Help Guide To Cerebral Palsy. Turkey: Mosly Elsevier

4. Borggraefe, Andreas M.H, Anita K, Jan S.C, Steffen B, and Florian H. 2008. Improved Gait Parameters After RoboticAssisted Locomotor Treadmill Therapy in a 6-Year-Old Child with Cerebral Palsy. Movement Disorders. Vol. 23.

5. de Saldanha S, do Pinho A.S, dos Santos C.G, de Souza P.A, 2014. Facilitation handlings induce increase in electromyographic activity of musclesn involved in head control of Cerebral Palsy. Research in Developmental Disabilities, 35 ; 2547-2557 DOI 10.1016/j.ridd.06.018

6. Wallard B, Bril G. Dietrich Y, Kerlirzin $\mathrm{J}$, Bredin. 2012. The role of head stabilization in locomotion in children with cerebral palsy. Annals of Physical Rehabilitation 55 590-600

7. Kourosh B. et all. 2017. Asian Spine Journal. The Effect of soft and rigid CervicalCollars on Head and Neck Immobilization in Healthy Subject

8. Wallard B, Bril G. Dietrich Y, Kerlirzin J, Bredin. 2012. The role of head stabilization in locomotion in children with cerebral palsy. Annals of Physical Rehabilitation 55 560-575

9. Einspieler C, Marschik P.B, Prechtl H.F.R, 2008. Human motor behavior. Prenatal origin and early postnatal development. Journal of Psychology, 216(3); 147-153 DOI 10.1027/00443409.216.3.147 
10. de Lima A.C.D, Tudella E, van der Kamp J, Savelsbergh G.J.P, 2014. Early development of head movements between birth and 4 months of age: A longitudinal study. Journal of Motor Behavior, 46:6; 415-422DOI:

10.1080/00222895.2014.92956

11. Hong J.S. 2017. New Ideas of Treatment for Cerebral Palsy I Capital Flexion of the Neck: the Key Link in PrematurityTreatment. David Publishing 